\title{
Improvement or selection? A longitudinal analysis of students' views about experimental physics in their lab courses
}

\author{
Bethany R. Wilcox ${ }^{1}$ and H. J. Lewandowski ${ }^{2,3}$ \\ ${ }^{1}$ Department of Physics, Colorado School of Mines, Golden, Colorado 80401, USA \\ ${ }^{2}$ Department of Physics, University of Colorado, 390 UCB, Boulder, Colorado 80309, USA \\ ${ }^{3}$ JILA, National Institute of Standards and Technology and University of Colorado, \\ Boulder, Colorado 80309, USA
}

(Received 12 June 2017; published 11 September 2017)

\begin{abstract}
Laboratory courses represent a unique and potentially important component of the undergraduate physics curriculum, which can be designed to allow students to authentically engage with the process of experimental physics. Among other possible benefits, participation in these courses throughout the undergraduate physics curriculum presents an opportunity to develop students' understanding of the nature and importance of experimental physics within the discipline as a whole. Here, we present and compare both a longitudinal and pseudolongitudinal analysis of students' responses to a research-based assessment targeting students' views about experimental physics-the Colorado Learning Attitudes about Science Survey for Experimental Physics (E-CLASS) — across multiple, required lab courses at a single institution. We find that, while pseudolongitudinal averages showed increases in students' E-CLASS scores in each consecutive course, analysis of longitudinal data indicates that this increase was not driven by a cumulative impact of laboratory instruction. Rather, the increase was driven by a selection effect in which students who persisted into higher-level lab courses already had more expertlike beliefs, attitudes, and expectations than their peers when they started the lower-level courses.
\end{abstract}

DOI: 10.1103/PhysRevPhysEducRes.13.023101

\section{INTRODUCTION}

Laboratory courses represent a unique component of the undergraduate physics curriculum. These courses can provide students opportunities to engage authentically with the process of experimental physics and learn practical lab skills. One implicit measure of the extent to which these courses are valued by the physics community is that the majority of undergraduate physics programs in the United States include at least two required lab courses. However, historically, little work has been done clearly demonstrating the effectiveness of these courses at achieving their learning goals [1-3]. Recently, demonstrating student learning in undergraduate lab courses has been the focus of additional attention from the physics education research community [4-6]. These studies have, to date, focused on measuring or comparing the effectiveness of individual lab courses.

While assessments of individual lab courses are necessary and useful, another important element of assessing the effectiveness of these courses is to take a longitudinal look at student learning as they advance through multiple courses in the undergraduate lab curriculum. A longitudinal investigation of this type could provide a more holistic view of whether and

Published by the American Physical Society under the terms of the Creative Commons Attribution 4.0 International license. Further distribution of this work must maintain attribution to the author(s) and the published article's title, journal citation, and DOI. how student learning is enhanced as they complete successive lab courses. This kind of longitudinal study has not been conducted previously in part because there are significant theoretical and practical barriers to such a study. For example, there are many possible learning goals for physics lab courses, including reinforcing students' understanding of physics concepts $[2,7,8]$; teaching students' practical lab skills such as troubleshooting, critical thinking, and measurement skills $[4,5,9,10]$; and fostering students' understanding of, and appreciation for, the nature and importance of experimental physics $[5,7,8,11]$. Longitudinal investigations of improvement in students' conceptual knowledge over multiple lab courses would be difficult given that the majority of lab courses at different levels (e.g., introductory to advanced) target a wide range of physics topics with only small overlap in the particular physics concepts used. While there is potentially more overlap in the practical lab skills targeted by courses at different levels of the curriculum, little work has been done developing strategies for assessing development of these skills within a single course [1] let alone across multiple courses at multiple levels.

Alternatively, the goal of fostering students' views and understanding of experimental physics and its place within the discipline is applicable to lab courses at all levels of the undergraduate curriculum. Additionally, an established and research-based assessment designed to measure improvements with respect to this goal in both introductory and advanced lab courses already exists. This assessmentknown as the Colorado Learning Attitudes about Science 
Survey for Experimental Physics (E-CLASS)—is described in more detail in Sec. II A. The importance of students' beliefs, attitudes, and expectations as a learning goal of lecture courses has been discussed extensively both for science education generally $[12,13]$ and physics education specifically $[14,15]$. Students' epistemologies and expectations have also been shown to be linked to other measures of student success such as performance, interest, and persistence in physics [16-18]. Helping students to cultivate expertlike views with respect to the nature and importance of experimental physics has also been called out as an important goal of undergraduate physics labs by both researchers $[5,11,19]$ and national organizations $[10,20]$.

The goal of this paper is to present an example exploration of longitudinal trends in students' views and expectations about the nature of experimental physics in their lab courses across the lab curriculum. Specifically, we utilize students' responses to the E-CLASS assessment collected over a period of four years in each of three required lab courses at a research university. The primary goal of this analysis is to determine whether the observed increase in average E-CLASS scores in each successive lab course is due to the impact of instruction or the result of a selection bias related to which students choose to pursue and persist in the physics program. After describing the courses and context (Sec. II), we present a longitudinal analysis of these data looking at individual students' scores as they progress through multiple lab courses (Sec. III). We conclude with a discussion of the limitations and implications of our findings for undergraduate lab education (Sec. IV).

\section{METHODS}

\section{A. The E-CLASS}

The E-CLASS is a research-based survey that probes students' views about the nature and importance of experimental physics. In the E-CLASS, students are asked to rate their level of agreement-from strongly agree to strongly disagree - to 30 statements, such as, "When doing an experiment, I just follow the instructions without thinking about their purpose." Students respond to each statement both from their own perspective when doing experiments in their laboratory course and from the perspective of a hypothetical experimental physicist. While students' predictions of experts is not scored, the paired format helps to disentangle students' personal views from what they believe the "correct" answer is. Numerical scores on each of the E-CLASS items are determined based on the established expertlike response for that item [21]. For each item, the responses "(dis)agree" and "strongly (dis)agree" were collapsed into a single (dis)agree category, and students were awarded +1 for favorable (i.e., consistent with experts), +0 for neutral, and -1 for unfavorable (i.e., inconsistent with experts). A student's overall E-CLASS score is given by the sum of their scores on each of the 30 items resulting in a possible range of scores of $[-30,30]$ [22].
Over approximately the last four years, the E-CLASS has been administered at more than 75 different institutions via a centralized, online administration system [23]. This national data set includes both introductory and upper-division courses from a variety of different institution types. We have previously presented the theoretical grounding, development, and validation of the E-CLASS [21,22]. We have also utilized this extensive data set to explore the role gender plays in performance on E-CLASS [24]. Additionally, we measured the impact of different types of lab activities on E-CLASS scores, where we found students in courses that included at least some open-ended activities outperformed students in courses with only guided labs [25]. Similarly, we have measured a significant improvement in E-CLASS scores in courses that use well-established transformed curricula compared to traditional labs at the introductory level, and the increase is significantly larger for women [26]. Finally, we have shown that courses that focus more on developing lab skills outperform courses that focus more on reinforcing physics concepts, and again, the increase is significantly larger for women [27].

\section{B. Context}

Data for this study were collected over eight consecutive semesters at the University of Colorado Boulder (CU). The undergraduate physics and engineering physics curriculum at $\mathrm{CU}$ includes three required lab courses, one at each the freshman, sophomore, and junior years, along with one additional optional lab course at the senior level. The seniorlevel, advanced lab course at CU covers topics in optics and modern physics and is offered as an alternative path for students to fulfill the requirement that all $\mathrm{CU}$ physics majors engage in research in order to graduate. Thus, students who take this course are almost exclusively physics students who have not had an undergraduate research experience either because they did not want one or because they were unable to secure one. The clear selection bias introduced by the optional nature of this senior lab course presents a significant challenge with respect to interpreting longitudinal trends; thus, this course has been removed from the overall data set. The following analysis will focus on data from CU's three required lab courses described below.

The introductory lab course at CU (PHYS 1140) is a one-credit course typically taken in the second semester of students' first year. While all physics and engineering physics majors are required to take this course, the student population is primarily engineering majors and other science majors such as biology and chemistry (see Table I). Students in PHYS 1140 complete six, two-week long experiments related to introductory mechanics and electricity and magnetism. The second lab course (PHYS 2150) is a one credit course typically taken during students' sophomore year. The student population is primarily physics and engineering physics majors with a smaller number of general engineering and other science majors (see Table I). Students in PHYS 
TABLE I. Breakdown of majors in each of CU's three required lab courses. Here, physics includes both physics and engineering physics majors, engineering includes all other engineering majors, other science includes math majors and all other science majors, and nonscience includes majors who are declared nonscience majors and students who are open-option or undeclared.

Course Physics Engineering Other science Non science Total

\begin{tabular}{rrrrrr}
\hline 1140 & $11 \%$ & $55 \%$ & $30 \%$ & $3 \%$ & 2306 \\
2150 & $71 \%$ & $4 \%$ & $23 \%$ & $1 \%$ & 188 \\
3330 & $94 \%$ & $0 \%$ & $5 \%$ & $0 \%$ & 221 \\
\hline \hline
\end{tabular}

2150 choose 6 of 12 possible modern physics experiments to complete throughout the semester. Both PHYS 1140 and 2150 are taught in a traditional guided lab format and a student's grade is primarily based on submission of a formal lab report. The final required course (PHYS 3330) is a two credit course typically taken during the students' junior year. The student population is almost exclusively physics and engineering physics majors (see Table I). Students in PHYS 3330 complete 10 guided lab activities and then the final 4-5 weeks of the semester are dedicated to a single openended project.

The E-CLASS was administered online both pre- and postinstruction during all eight semesters of both PHYS 1140 and 3330. Because of logistical issues outside the control of the research team, the E-CLASS was only administered during five of the eight semesters in PHYS 2150. Instructors for the courses typically offered a small amount of participation credit to encourage students to complete the assessment. Instructors never received students' raw responses; instead, they received a list of students who participated and a summary of their students' responses in aggregate. Students' responses were matched, both pre- to postinstruction and between courses, first by student ID numbers and then by first and last name when ID matching failed.

Within our data set, there are both students who are fully longitudinal and students who are partially longitudinal (see Table II). By fully longitudinal, we mean that these students have matched pre- and postinstruction responses in all three lab courses. Only 33 students in our data set are fully longitudinal. Partially longitudinal students are students who have matched E-CLASS responses from at least two of the three lab courses (note that this means the fully longitudinal students are also included in the partially longitudinal population). Students in the partially longitudinal population include students for whom we have preand postinstruction responses from both PHYS 1140 and $2150(N=106)$, both PHYS 2150 and $3330(N=63)$, or both PHYS 1140 and $3330(N=61)$. Any student for whom we have both PHYS 1140 and 3330 data had to have taken and passed PHYS 2150. Thus, regardless of whether we have matched E-CLASS data from them in PHYS 2150, these students also provide a fully longitudinal view of whether (and how) students' E-CLASS scores change
TABLE II. Number of students in each of the three partially longitudinal populations in our data. The 33 students for whom we have fully longitudinal data are included in all applicable partially longitudinal populations, and thus appear multiple times in these counts.

\begin{tabular}{lcc}
\hline \hline & PHYS 1140 & PHYS 2150 \\
\hline PHYS 2150 & 106 & $\ldots$ \\
PHYS 3330 & 61 & 63 \\
\hline \hline
\end{tabular}

over the course of all three lab courses at CU. In the following analysis, we examine each of these three longitudinal populations separately and compare them with the full pseudolongitudinal population of each course. Here, the pseudolongitudinal population refers to the full population of students in each course; in other words, the pseudolongitudinal analysis looks at changes in the overall averages of consecutive courses without attempting to match students between courses.

\section{RESULTS}

Pseudolongitudinal data would be sufficient to determine the impact of the lab curriculum on students' E-CLASS scores if selection effects as students advance through the curriculum are not significant. This is an attractive possibility as pseudolongitudinal data are significantly easier and faster to collect. Table III reports the overall pre- and postinstruction E-CLASS averages for the full population of students who took each lab course during data collection. There are several interesting features of these data, including the fact that all courses show a negative or neutral shift from pre- to postinstruction, with no positive shifts. In contrast, Table III also indicates a steady increase in students' preinstruction averages in the higher level courses. This motivates the question, what is the source of these preinstruction increases given that the overall shift in individual courses is negative or neutral? To address this, we examine scores of students for whom we have longitudinal data.

Table IV presents the average E-CLASS scores for students in each of the longitudinal populations. For all three populations, the students for whom we have longitudinal data start and end the lower level course with higher E-CLASS scores than the general population in that

TABLE III. Pseudolongitudinal E-CLASS averages (max score 30) for all students who took each lab course during the data collection period. Pre- to postinstruction shifts are statistically significant (Mann-Whitney U [28] $p<0.05$ ) for both PHYS 1140 and 2150 .

\begin{tabular}{lccc}
\hline \hline & PHYS 1140 & PHYS 2150 & PHYS 3330 \\
\hline Pre & 18.1 & 19.5 & 20.1 \\
Post & 15.8 & 17.6 & 20.2 \\
$N$ & 2306 & 188 & 221 \\
\hline \hline
\end{tabular}


TABLE IV. Overall E-CLASS averages (max score 30) for students in each of the three longitudinal populations. The longitudinal students $(L)$ represent students for whom we have matched pre- and postinstruction responses in both courses in question. The general students $(G)$ represent all students for whom we have matched pre- and postinstruction responses for only the given course (minus the longitudinal students). Differences between scores for longitudinal and general students in a given course are statistically significant (Mann-Whitney $\mathrm{U} p<0.05$ ) for the lower level of the two course in all cases except one (denoted by asterisks), while the same difference for the higher level of the two courses is statistically insignificant in all cases.

\begin{tabular}{|c|c|c|c|c|c|c|c|c|c|c|c|c|}
\hline \multirow[b]{3}{*}{ Course } & \multicolumn{4}{|c|}{ PHYS 1140 to 2150} & \multicolumn{4}{|c|}{ PHYS 1140 to 3330} & \multicolumn{4}{|c|}{ PHYS 2150 to 3330} \\
\hline & \multicolumn{2}{|c|}{1140} & \multicolumn{2}{|c|}{2150} & \multicolumn{2}{|c|}{1140} & \multicolumn{2}{|c|}{3330} & \multicolumn{2}{|c|}{2150} & \multicolumn{2}{|c|}{1140} \\
\hline & $L$ & $G$ & $L$ & $G$ & $L$ & $G$ & $L$ & $G$ & $L$ & $G$ & $L$ & $G$ \\
\hline Pre & 20.4 & 18.0 & 19.6 & 19.4 & 21.0 & 18.0 & 20.6 & 20.0 & $20.6 *$ & $18.9 *$ & 20.3 & 20.1 \\
\hline Post & 19.3 & 15.7 & 17.3 & 18.1 & 21.0 & 15.7 & 21.0 & 20.0 & 18.8 & 16.9 & 20.6 & 20.1 \\
\hline$N$ & 106 & 2220 & 106 & 82 & 61 & 2245 & 61 & 160 & 63 & 125 & 63 & 158 \\
\hline
\end{tabular}

course. This difference in scores is statistically significant (Mann-Whitney $\mathrm{U}[28] p<0.05$ ) in all cases except onethe preinstruction score for the longitudinal students in PHYS 2150 is statistically the same as that of the general 2150 students. Moreover, for all three populations, the longitudinal students start and end the higher level course with overall E-CLASS scores that are statistically indistinguishable (Mann-Whitney U $p>0.05$ ) from the scores of the general population of that course. These trends suggest that the increase in students' scores in the higher level lab courses observed in the pseudolongitudinal data (see Table III) is strongly, if not entirely, driven by a selection effect. Students that persist into higher level courses, started out more expertlike than their peers who did not persist, and their views stayed roughly constant throughout the curriculum.

Because only the physics and engineering physics majors are required to take courses beyond PHYS 1140, these students are oversampled in the longitudinal PHYS 1140 populations relative to the general 1140 population. Thus, there are two potential selection effects at work. The first is related to which students select into the physicsrelated majors, and the second is related to which students persist between courses independent of major. Determining the extent to which each of these selection effects comes into play could include analysis of just the longitudinal students who are physics majors. Our data set is not large enough to make strong statistical claims about the longitudinal physics and nonphysics populations separately. However, a preliminary look at the general trends in our sample showed that while the physics students have slightly higher averages overall, the longitudinal trends were not meaningfully different between these two populations. If robust, this finding would suggest that a selection effect relating to which students persist between courses was significant independent of major.

\section{CONCLUSIONS}

Using a research-based assessment (E-CLASS), we investigated longitudinal trends in students' beliefs about the nature and importance of experimental physics as they progress through the required laboratory curriculum at a large, very high research institution. We collected pre- and postinstruction E-CLASS data from eight semesters of three consecutive lab courses that are required for all physics and engineering physics majors. Using these data, we demonstrated that, while pseudolongitudinal averages showed increases in students' E-CLASS scores in each consecutive course, analysis of longitudinal data indicates that this increase was not driven by a cumulative impact of laboratory instruction, but rather a selection effect in which students who persisted into higher level lab courses had started their lower level courses with more expertlike beliefs, attitudes, and expectations (as measured by ECLASS) than their peers. This finding is consistent with prior work investigating longitudinal trends in a related assessment targeting students attitudes and beliefs in lecture physics courses, The Colorado Learning Attitudes about Science Survey [14,29].

One important implication of this finding is to underscore the importance of truly longitudinal data when investigating the impact of instruction across multiple courses. While previous studies have found matching trends between longitudinal and pseudolongitudinal data [30], our findings suggest that this is not always the case and should not be assumed. The work described here has several important limitations. This investigation was conducted at a single institution with a fairly traditional lab curriculum. Our findings may not generalize to physics programs that have a significantly different student population or lab curriculum. For example, our prior work investigating E-CLASS scores at multiple institutions suggests that programs that include a significant number of open-ended activities throughout the curriculum, or utilize research-based instructional approaches may show different trends $[25,26]$. However, our findings do suggest that for programs with a largely traditional lab curriculum, participation in these courses is not encouraging more expertlike views, but rather selecting in favor of students whose views are already consistent with those of experts. 


\section{ACKNOWLEDGMENTS}

This work was funded by the NSF-IUSE Grant No. DUE-1432204 and NSF Grant No. PHY-1734006. Particular thanks to the members of PER@C for all their help and feedback.

[1] S. R. Singer, N. R. Nielsen, and H. A. Schweingruber, Discipline-Based Education Research: Understanding and Improving Learning in Undergraduate Science and Engineering (National Academies Press, Washington, DC, 2012).

[2] C. Wieman and N. G. Holmes, Measuring the impact of an instructional laboratory on the learning of introductory physics, Am. J. Phys. 83, 972 (2015).

[3] N. G. Holmes, J. Olsen, J. L. Thomas, and C. E. Wieman, Value added or misattributed? A multi-institution study on the educational benefit of labs for reinforcing physics content, Phys. Rev. Phys. Educ. Res. 13, 010129 (2017).

[4] N. G. Holmes, C. E. Wieman, and D. A. Bonn, Teaching critical thinking, Proc. Natl. Acad. Sci. U.S.A. 112, 11199 (2015).

[5] B. M. Zwickl, N. Finkelstein, and H. J. Lewandowski, The process of transforming an advanced lab course: Goals, curriculum, and assessments, Am. J. Phys. 81, 63 (2013).

[6] S. DeVore, A. Gauthier, J. Levy, and C. Singh, Development and evaluation of a tutorial to improve students' understanding of a lock-in amplifier, Phys. Rev. Phys. Educ. Res. 12, 020127 (2016).

[7] S. R. Singer, M. L. Hilton, H. A. Schweingruber et al., America's Lab Report: Investigations in High School Science (National Academies Press, Washington, DC, 2006).

[8] R. Millar, The role of practical work in the teaching and learning of science, High school science laboratories: Role and vision (National Academy of Sciences, Washington, DC, 2004).

[9] D. R. Dounas-Frazer and H. J. Lewandowski, Electronics lab instructors' approaches to troubleshooting instruction, Phys. Rev. Phys. Educ. Res. 13, 010102 (2017).

[10] AAPT Committee on Laboratories, AAPT Recommendations for the Undergraduate Physics Laboratory Curriculum, (American Association of Physics Teachers, College Park, MD, 2015).

[11] R. Trumper, The physics laboratory - a historical overview and future perspectives, Sci. \& Educ. 12, 645 (2003).

[12] B. K. Hofer and P. R. Pintrich, The development of epistemological theories: Beliefs about knowledge and knowing and their relation to learning, Rev. Educ. Res. 67, 88 (1997).

[13] A. Elby, Defining personal epistemology: A response to and, J. Learn. Sci. 18, 138 (2009).

[14] W. K. Adams, K. K. Perkins, N. S. Podolefsky, M. Dubson, N. D. Finkelstein, and C. E. Wieman, New instrument for measuring student beliefs about physics and learning physics: The Colorado Learning Attitudes about Science Survey, Phys. Rev. ST Phys. Educ. Res. 2, 010101 (2006).

[15] E. F. Redish, J. M. Saul, and R. N. Steinberg, Student expectations in introductory physics, Am. J. Phys. 66, 212 (1998).

[16] K. Perkins, M. Gratny, W. Adams, N. Finkelstein, and C. Wieman, Towards characterizing the relationship between students' interest in and their beliefs about physics, AIP Conf. Proc. 818, 137 (2005).
[17] K. Perkins, J. Barbera, W. Adams, and C. Wieman, Chemistry vs physics: A comparison of how biology majors view each discipline, AIP Conf. Proc. 883, 53 (2006).

[18] K. Perkins, W. Adams, S. Pollock, N. Finkelstein, and C. Wieman, Correlating student beliefs with student learning using the colorado learning attitudes about science survey, AIP Conf. Proc. 790, 61 (2004).

[19] R. Feynman, Goals of the introductory physics laboratory, Am. J. Phys. 66, 483 (1998).

[20] S. Olson and D. Gerardi Riordan, Engage to Excel: Producing One Million Additional College Graduates with Degrees In Science, Technology, Engineering, and Mathematics. Report to the President, (Executive Office of the President, Washington, DC, 2012).

[21] B. M. Zwickl, T. Hirokawa, N. Finkelstein, and H. J. Lewandowski, Epistemology and expectations survey about experimental physics: Development and initial results, Phys. Rev. ST Phys. Educ. Res. 10, 010120 (2014).

[22] B. R. Wilcox and H. J. Lewandowski, Students' epistemologies about experimental physics: Validating the colorado learning attitudes about science survey for experimental physics, Phys. Rev. Phys. Educ. Res. 12, 010123 (2016).

[23] B. R. Wilcox, B. M. Zwickl, R. D. Hobbs, J. M. Aiken, N. M. Welch, and H. J. Lewandowski, Alternative model for administration and analysis of research-based assessments, Phys. Rev. Phys. Educ. Res. 12, 010139 (2016).

[24] B. R. Wilcox and H. J. Lewandowski, Research-based assessment of students' beliefs about experimental physics: When is gender a factor?, Phys. Rev. Phys. Educ. Res. 12, 020130 (2016).

[25] B. R. Wilcox and H. J. Lewandowski, Open-ended versus guided laboratory activities: Impact on students' beliefs about experimental physics, Phys. Rev. Phys. Educ. Res. 12, 020132 (2016).

[26] B. Wilcox and H. J. Lewandowski, Impact of instructional approach on students' epistemologies about experimental physics, Proceedings of the Physics Education Research Conference 2016, Sacramento, CA (AIP, New York, 2016).

[27] B. R. Wilcox and H. J. Lewandowski, Developing skills versus reinforcing concepts in physics labs: Insight from a survey of students' beliefs about experimental physics, Phys. Rev. Phys. Educ. Res. 13, 010108 (2017).

[28] H. B. Mann and D. R. Whitney, On a test of whether one of two random variables is stochastically larger than the other, Ann. Math. Stat. 18, 50 (1947).

[29] E. Gire, B. Jones, and E. Price, Characterizing the epistemological development of physics majors, Phys. Rev. ST Phys. Educ. Res. 5, 010103 (2009).

[30] K. Slaughter, S. Bates, and R. Galloway, A longitudinal study of the development of attitudes and beliefs towards physics, AIP Conf. Proc. 1413, 359 (2011). 